\title{
Tamoxifen added to lumpectomy and radiation therapy reduced breast cancer events in ductal carcinoma in situ
}

Fisher B, Dignam J, Wolmark N, et al. Tamoxifen in treatment of intraductal breast cancer: National Surgical Adjuvant

Breast and Bowel Project B-24 randomised controlled trial. Lancet 1999 Jun 12;353:1993-2000.

QUESTION: In women with non-invasive ductal carcinoma in situ (DCIS), does adding tamoxifen to lumpectomy and radiation therapy (RT) prevent cancer in ipsilateral and contralateral breasts?

\section{Design}

Randomised \{allocation concealed $*\}, \uparrow$ blinded \{clinicians, patients, outcome assessors, and statisticians*\}, $\uparrow$ placebo controlled trial with median 74 month follow up.

\section{Setting}

57 centres in the United States and Canada.

\section{Patients}

1804 women who had lumpectomy for DCIS, including those with or without lobular carcinoma in situ, and who were expected to live $\geq 10$ years. $16 \%$ had positive resection margins. Women with previously diagnosed cancer other than in situ carcinoma of the cervix or basal cell or squamous cell carcinoma of the skin were excluded. Follow up was $99.7 \%$.

\section{Intervention}

Lumpectomy and RT (50 Gy) began within 8 weeks of surgery and were allocated to tamoxifen, $10 \mathrm{mg}$ twice/d for 5 years $(n=902)$, or placebo $(n=902)$.

\section{Main outcome measures}

Invasive or non-invasive tumours as first events in the ipsilateral or contralateral breast.

\section{Main results}

Fewer breast cancer events, both invasive and noninvasive, occurred in women who received tamoxifen than in those who received placebo $(\mathrm{p}<0.001)$ (table). Use of tamoxifen reduced invasive events in the ipsilateral breast $(p=0.03)$ and non-invasive events in the contralateral breast $(p=0.02)$ (table). For total breast cancer events, 20 women would need to be treated with tamoxifen for 5 years to prevent 1 additional occurrence of breast cancer. At 5 years, survival was $97 \%$ in each group $(\mathrm{p}=0.74)$.

\section{Conclusion}

In women with ductal carcinoma in situ, the addition of tamoxifen to a treatment regimen of lumpectomy and radiation therapy was effective in preventing cancer in the ipsilateral and contralateral breast at 5 years without affecting survival.

*See glossary.

$\dagger$ Information provided by author.

\section{COMMENTARY}

Fisher and colleagues show that tamoxifen therapy for 5 years adds to the benefit of lumpectomy and radiation in women with DCIS. Some parts of this study, however, merit discussion before it can be concluded that tamoxifen should be recommended for all women with DCIS.

Tamoxifen decreased the rate of invasive breast cancer in the ipsilateral breast (absolute reduction of 2.1\%, from $4.2 \%$ to $2.1 \%)$. For enrolment, pathological margins of resection for cancer could be either negative or positive, and $16 \%$ of patients had involved residual surgical margins. Patients with residual scattered mammographic calcifications were also eligible for enrolment. Margins of resection have been shown to correlate with recurrence in previous retrospective studies. For example, a non-randomised trial by Silverstein and colleagues $^{1}$ showed only a $4 \%$ risk for 8 year ipsilateral recurrence with lumpectomy alone in women whose excised lesions had margin widths of $\geq 10 \mathrm{~mm}$. The benefit of tamoxifen might have been lower if the margins of resection were negative, if patients with suspicious residual calcifications had had further surgery, or if an RT boost to the tumour bed had been given to those with positive resection margins.

Although tamoxifen led to a decrease in non-invasive contralateral DCIS, the absolute reduction was $0.9 \%$ (from $1.1 \%$ to $0.2 \%$ ), and no significant effect was seen on the rate of contralateral invasive disease.

Tamoxifen appears appropriate for some women with DCIS, but perhaps not for all. Further well designed trials should attempt to define the subsets of women who will benefit most from this systemic therapy.

Edith A Perez, MD Mayo Clinic Jacksonville Jacksonville, Florida, USA

1 Silverstein MJ, Lagios MD, Groshen S, et al. $N$ Engl J Med 1999:340:1455-61.

\section{Author's response}

The points raised by Dr Perez regarding positive margins are similar to those recently published in a letter to the Lancet, to which we gave a detailed response.

Bernard Fisher, MD

1 Chan KC, Bundred NJ. Lancet 1999;354:1211-2.
Lumpectomy, radiation therapy (RT), and tamoxifen v lumpectomy, RT, and placebo to prevent first breast cancer events at 5 years $\$$

\begin{tabular}{llll} 
& \multicolumn{2}{l}{ Cumulative incidence of events } & \\
\cline { 2 - 3 } Events & Tamoxifen & Placebo & $\begin{array}{l}\text { Relative event } \\
\text { reduction }(95 \% \mathrm{Cl})\end{array}$ \\
All breast cancer & $8.2 \%$ & $13.4 \%$ & $37 \%(17$ to 53$)$ \\
\hline Ipsilateral breast cancer & & & \\
\hline$\quad$ Invasive & $2.1 \%$ & $4.2 \%$ & $44 \%(5$ to 68$)$ \\
\hline$\quad$ Non-invasive & $3.9 \%$ & $5.1 \%$ & $18 \%(-28$ to 47$) \ddagger$ \\
\hline Contralateral breast cancer & & & $37 \%(-26$ to 69$) \ddagger$ \\
\hline$\quad$ Invasive & $1.8 \%$ & $2.3 \%$ & $78 \%(19$ to 96$)$ \\
\hline$\quad$ Non-invasive & $0.2 \%$ & $1.1 \%$ &
\end{tabular}

Sources of funding: National Institutes of Health;Department of Health and Human Services.

For correspondence: Prof B Fisher, National Surgical Adjuvant Breast and Bowel Project (NSABP), 4 Allegheny Center, Suite 602, Pittsburgh, PA 15212-5234, USA. Fax +1412330 4411. 